\title{
THE EFFECT OF TEMPERATURE PYROLYSIS PROCESS OF USED TIRES ON THE QUALITY OF OUTPUT PRODUCTS
}

\author{
Natália JASMINSKÁ*, Tomáš BRESTOVIČ゙, Mária ČARNOGURSKÁ* \\ *Faculty of Mechanical Engineering, Technical University in Kosice, Vysokoškolská 4, 04200 Košice, Slovak Republik \\ natalia.jasminska@tuke.sk, tomas.brestovic@tuke.sk, maria.carnogurska@tuke.sk
}

\begin{abstract}
Pyrolysis together with gasification and combustion create a group of so called thermic processes. Unlike the combustion it is based on thermic decomposition of organic materials without any access of oxidative media. Within the pyrolytic process, three main fractions are created: solid residue, pyrolytic gas and organic liquid product - pyrolytic oil. The presented article examines the effects of pyrolysis operational conditions (above all, temperature) on gas products, solid residues and liquid fractions.
\end{abstract}

Key words: Pyrolysis, Pyrolysis, Used Tires, Temperature, Pyrolytic Gas, Pyrolytic Oil, Solid Residue

\section{INTRODUCTION}

Pyrolysis offers ecologically attractive method of decomposition and estimation of a wide scale of waste, including used tires. Processing of used tires by pyrolysis means their thermal degradation occurring without presence of oxygen. In the pyrolysis process organic volatiles from the tires (approximately $60 \%$ ) are decomposed into low molecular weight products, liquids or gases that could be subsequently used as fuels or chemicals (Wagnerová et al., 2003). Non-volatile soots and inorganic components (approximately $40 \%$ ) remain in the solid residue and can be recycled in different technological applications.

The benefit of this technology is a transformation of used tires to secondary raw materials such as olefins or active carbon. The biggest obstructions in wider usage of pyrolysis are high economical costs and technological demands of the process. The capital costs are too high in comparison with the value of pyrolysis output products. Development of less demanding technology or production of higher value products out of pyrolytic processes enable pyrolysis to become an equal alternative for recycling of used tires. The positives of this technology are low emission values in produced gas which means minimal negative effect on the environment (Aylón et al., 2007).

\section{GENERAL CHARACTERISTICS OF THE PYROLYTIC PROCESS}

Pyrolysis is a thermo-chemical distillation process within which heat is transported into a hermetically closed space filled with fuel. Here, hydrocarbons are fissured and formed to combustible gases, distillation products and carbonated residue (Cunliffe et al., 1998). Combustible gases and distillation products are subsequently used as, for example, fuel. The process is usually run in a so called pyrolytic furnace or also in a coking chamber. The process of pyrolysis is in progress at the temperature of 250 to $1100{ }^{\circ} \mathrm{C}$ with prevention of air access. There is a gradual thermal decomposition where undesirable toxic matters are usually thermally decomposed into better modifiable matters or into harmless compounds. Frequently, compound of hydrocarbons and soots is gained. Within organic matters, it is mainly carbon dioxide $\left(\mathrm{CO}_{2}\right)$ and water. The liquid element of pyrolysis is called pyrolytic oil and the gas element is pyrolytic gas.

Recycling process by pyrolysis has two basic stages:

1. Self pyrolysis. It is a thermal decomposition of crushed input matters at high temperatures without air access.

2. Pyrolytic product processing. By pyrolytic oil separation it is possible to obtain secondary materials such as benzene, toluene, xylene and the like.

According to the temperature at which the pyrolytic process is run we distinguish:

- low-temperature pyrolysis (reaction temperature up to $500^{\circ} \mathrm{C}$ ),

- middle-temperature pyrolysis (reaction temperature in the range of 500 up to $800{ }^{\circ} \mathrm{C}$ ),

- high-temperature pyrolysis (reaction temperature over $800^{\circ} \mathrm{C}$ ).

The own course of pyrolytic process lying in smaller molecules fission out of the original molecules with long chains depends on the type and characteristics of processed material (Muren et al., 1996).

Within the pyrolytic process there are, depending on temperature, different actions which can be, in a simplified way, divided into three thermal intervals.

1. Within temperatures up to $200{ }^{\circ} \mathrm{C}$ material is being dried and water steam is created - this is an endothermic process.

2. Within temperatures from 200 up to $500{ }^{\circ} \mathrm{C}$ there is a part of so called dry distillation. Here, side chains from the highmolecular organic matters are split off and macromolecular structures are transformed to gas and liquid organic products and to solid carbon.

3. In the phase of gas creation within temperatures from 500 up to $1200^{\circ} \mathrm{C}$ products that were created by a dry distillation are being fissioned and transformed. Pyrolytic gas, oils and charcoal are the primary products of this process (Tab. 1) (Rodriguez et al., 2001). 
After pyrolysis, the solid residue contains soots and minerals. The liquid fraction is created by a very complicated composition of organic compounds.

Tab. 1. Products of pyrolysis process

\begin{tabular}{|c|c|c|c|}
\hline $\begin{array}{c}\text { Primary } \\
\text { products }\end{array}$ & Weight \% & Content & Secondary products \\
\hline pyrolytic gas & $10-30$ & $\begin{array}{c}\mathrm{H}_{2}, \mathrm{CO}_{2}, \mathrm{CO} \text {, methane, ethane, propane, propene, } \\
\text { butane, other hydrocarbons, approximately } 1 \% \text { of } \\
\text { sulfur }\end{array}$ & - \\
\hline pyrolytic oil & $40-60$ & $\begin{array}{c}\text { Low value of sulfur (0.3 }-0.1 \%), \\
\text { aromatic hydrocarbons, alkanes, alkenes, ketones } \\
\text { and aldehydes }\end{array}$ & $\begin{array}{c}\text { soots } \\
\text { (carbon slack) }\end{array}$ \\
\hline charcoal & $30-40$ & $>15 \%$ of ash (containing ZnO), 3-5\% of sulfur. & active carbon \\
\hline
\end{tabular}

Oils and charcoal undergo other processes in order to gain more valuable products out of them. Improving qualities of charcoal is obtained by a multilevel activation with a final product of carbon with high active surface. Its other benefit is also elimination of undesirable side products and emissions. The oil with a low level of ash is transformed into high-quality soots or as an alternative, oil separation using distillation and their usage in chemical industry is an option. Gas product - pyrolytic gas is created by non-condensed organic elements and compounds $\mathrm{H}_{2}, \mathrm{H}_{2} \mathrm{~S}, \mathrm{CO}$, $\mathrm{CO}_{2}, \mathrm{CH}_{4}, \mathrm{C}_{2} \mathrm{H}_{4}, \mathrm{C}_{3} \mathrm{H}_{6}$ and other light hydrocarbons. Subsequently, it is possible to use the pyrolytic gas as fuel in the process of pyrolysis. The volume and content of these three fractions depend on processing parameters (temperature, speed of heating, pressure, time, size and characteristics of the input material and so on), at volatile fraction, condensing temperature is a crucial parameter (Kizek et al., 1999).

Technologies that produce high-quality pyrolytic oil on the basis of fast pyrolysis have recently entered commercial levels. The main area of using the high-quality pyrolytic oil is biochemistry. Here, research of its usage is carried out - as an alternative fuel for slow-running ships and the like high-capacity diesel engines or combustion turbines.

\subsection{Thermal decomposition of used tires}

In order to study thermic degradation of tire rubber samples waste, standard methods are used:

- thermogravimetry (TG),

- derivative thermogravimetry (DTG).

Out of the thermogravimetric analysis listed according to different authors (e.g. Leung and Wang et al. 1998; Berrueco et al. 2005; Yang et al. 1995) it is clear that during pyrolysis there is more than one material decomposition influenced by temperature. It is confirmed also by experimental measurements that have been carried out (Fig. 1) (Koreňová et al., 2006; Haydara et al., 2012).

The result of decomposition influences mainly the composition of rubber compound. Measured thermogravimetric (TG) curves show two different weight losses in the temperature range from 250 to $550^{\circ} \mathrm{C}$. On the basis of the individual characteristics of tire rubber parts thermal decomposition in the temperature range of 250 up to $380{ }^{\circ} \mathrm{C}$ there is evaporation of additives, oil and softening agents. With the temperature interval of 400 up to 550 ${ }^{\circ} \mathrm{C}$ there is decomposition of natural rubber (NR), styrenebutadiene rubber (SBR) and polybutadiene rubber (BR).

A typical sample weight loss obtained within measurement is listed in Fig. 2.

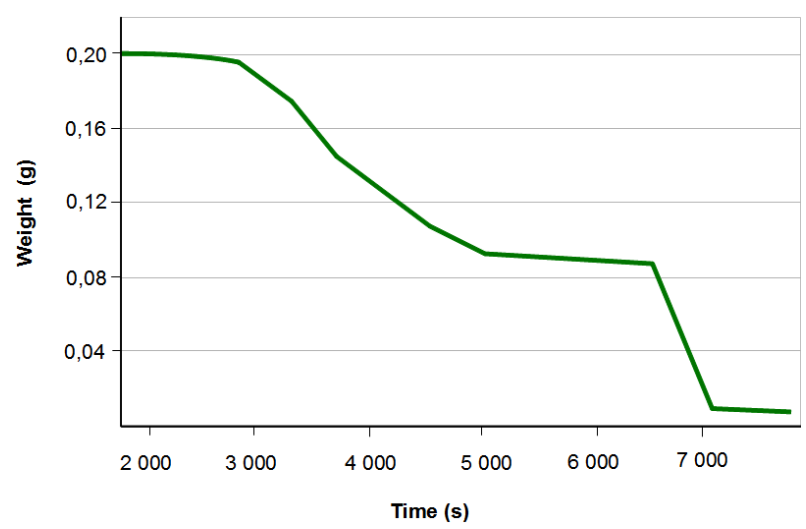

Fig. 1. Process of sample weight loss of the used tire depending on time

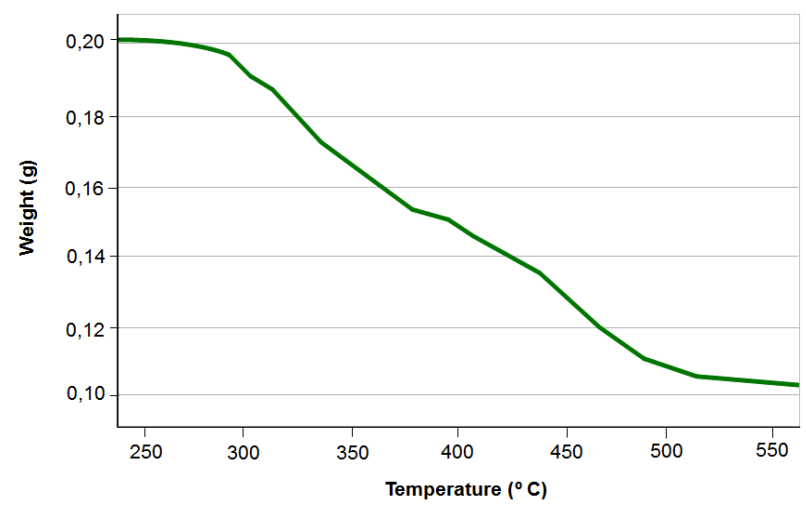

Fig. 2. Thermal degradation of the used tire residue

\section{METHODOLOGY OF THE EXPERIMENT}

Preparation of the sample lies in mechanical division of rubber, textile (polymer) and metal parts of the tire. The rubber part of the tire is inserted into a shredder where its size is reduced to approximately $15 \mathrm{~cm}$ big parts.

In the experimental research of pyrolytic process of used tires liquidation, rubber grit from used tires of cars and trucks was used (sample marked RR) as well as polymer fibers, gained at tire mechanical modification (sample marked PF).

At the thermic degradation of used tires, it is crucial to know the combustion heat of the particular material and its calorific value. Before the test of pyrolytic process of decomposition there were calorimetric measurements carried out in order to set combustion heat for each tire sample individually. The final value represents an average value out of the three calorimetric measurements. For the purpose of control of the laboratory results at the department, an elemental analysis in external laboratory was carried out. Elemental analysis of laboratory tests samples carried out at the department is listed in Tab. 2.

Tab. 2. Elemental analysis of used tires rubber grit

\begin{tabular}{|c|c|c|c|c|c|c|c|}
\hline Sample & $\mathbf{C}^{d}$ & $\mathrm{H}^{d}$ & $\mathbf{N}^{d}$ & $\mathbf{S}^{d}$ & Od $^{d}$ & Ashd $^{d}$ & $Q_{\mathrm{S}}^{*}$ \\
\hline \multicolumn{7}{|c|}{ (\% weight) } \\
\hline RR & 87.6 & 7.6 & 0.3 & 2.01 & 3.1 & 9.3 & $\left(\mathbf{M J} \cdot \mathbf{k g}^{-1}\right)$ \\
\hline PF & 83.6 & 7.2 & 0.3 & 1.75 & 7.8 & 8.4 & 32.75 \\
\hline
\end{tabular}

Values of the individual elements gained in the elemental analysis (Cd-carbon Hd-hydrogen, Nd-nitrogen, Sd-sulfur, Od- oxygen), $Q_{\mathrm{S}}{ }^{*}$ - combustion heat gained in calorimetric measurement 


\subsection{Experimental device}

In order to propose the experimental device for monitoring the pyrolysis process it is necessary to consider operational conditions of the technological pyrolysis process and technical solution of the experimental device:

1. Conditions of pyrolysis process:

- non-oxidative environment,

- type of reaction chamber,

- material heating up (speed of heating up).

2. Conditions of technical solution

- material quantization,

- collection of pyrolytic products (solid residues, liquid fraction, gas compound).

From the above mentioned conditions for the process of py- rolysis it is necessary to provide that the experimental sample is in a non-oxidative atmosphere. For creating a non-oxidative atmosphere it is possible to use inert gas (nitrogen) with the purity of $99.9 \%$ which is suitable to use due to its characteristics. The choice of using nitrogen in order to create a non-oxidative atmosphere has already been confirmed in various works from the area of pyrolytic process laboratory research. Nitrogen is delivered into the reaction chamber from a pressure vessel. Thermal energy needed for a thermal decomposition is gained from electric resistance heating. At experimental conditions, a continuous operation is not considered and it is the reason for the construction of reactor with stationary horizontal bed containing SiC-rod with a diameter of $30 \mathrm{~mm}$ and length of $600 \mathrm{~mm}$. The scheme of experimental pyrolytic device is shown in the Fig. 3. The device is located in the laboratory at the Department of Power Engineering.

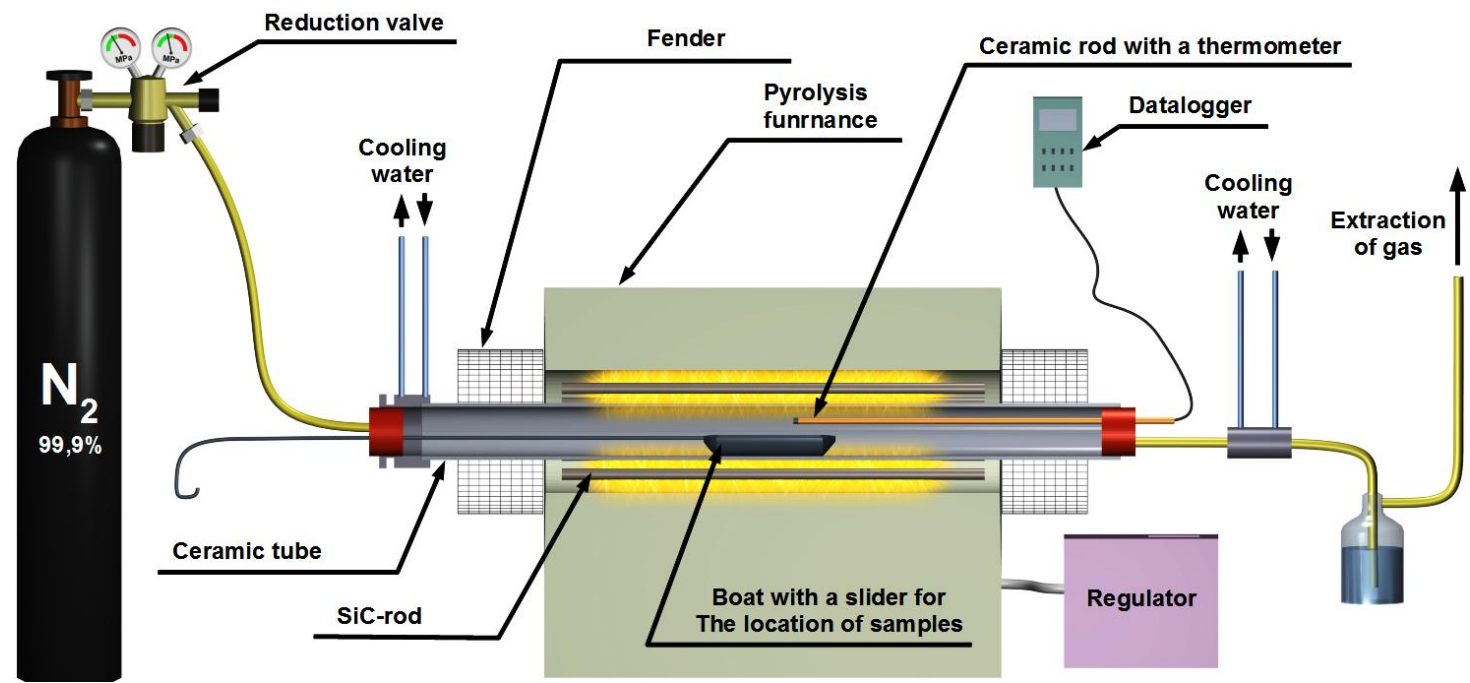

Fig. 3. The scheme of laboratory pyrolytic device

The procedure at the experiment is following:

- measured waste sample is inserted into a dosing device and it is placed into the entrance chamber of the device,

- cooling system of the entrance chamber is on and its sealing is determined,

- after controlling the sealing, all system is rinsed by nitrogen from a pressure device which enables to create working nonoxidative environment,

- it is necessary to carry out the rinsing for approximately 10 minutes which is a proper time for eliminating atmospheric air that entered the system after locating the sample into the entrance chamber,

- the flow of nitrogen is stopped by a closing valve,

- a three-way valve serves for connecting the U-tube with all system of the experimental device (U-tube serves for the sealing control of all system). Change in pressure means no sealing in the system,

- after setting the sealing, heating of reactor's reaction zone is turned on. It consists of inner part of silica tube. Heating is provided by a resistance furnace. The furnace heating is regulated by a TC-31 regulator and temperature in the reaction furnace zone is controlled by a thermocouple type $S$ with an output for a digital thermometer Testo 945. Time interval of temperature registering is selectable. In case of this experi- ment, it was 1 minute. Also temperature of furnace's surface is registered using contact thermometer with an output for ALMEMO 2290.

- after heating the furnace and after temperatures' consolidation in the reaction zone, it is possible to start to monitor the pyrolysis process,

- before placing the sample into the reaction zone, the threeway valve was turned to a position of flow of created gas to graduated bottle, thus the U-tube was disconnected from all of the system.

Monitoring of the pyrolytic process was carried out by three different manners. The first manner represented so called "fast pyrolysis". Here, the sample was heated to the temperature of $600{ }^{\circ} \mathrm{C}$ at the heating speed of $10^{\circ} \mathrm{C} \cdot \mathrm{min}^{-1}$. In the second manner, sample heating was carried out by a so called "fast pyrolysis" to the temperature of $800^{\circ} \mathrm{C}$. In the third manner the sample was heated by a "fast pyrolysis" to $600^{\circ} \mathrm{C}$ and then by a "slow pyrolysis" to $800^{\circ} \mathrm{C}$ at heating speed of $2^{\circ} \mathrm{C} \cdot \mathrm{min}^{-1}$.

Out of the produced pyrolytic gas, a condensate is captured in the gas cooler and gas in the graduated bottle and also its volume is registered. Gas volume is registered at its production which starts at a temperature range of 200 up to $250{ }^{\circ} \mathrm{C}$.

Time interval of volume registering was 1 minute - until the furnace was turned off. In order to avoid distortion of real pyrolytic 
gas composition, all devices is rinsed by nitrogen in volume of 1.0 to $1.3 \mathrm{dm}^{3}$ after the process is finished. Nitrogen enables to capture the gas product that remained in the reaction zone. Rinsing is carried out until the furnace temperature in the reaction zone decreases below $200{ }^{\circ} \mathrm{C}$. After opening the entrance chamber, a sample of solid residue is taken; it is measured on analytical scales and prepared for the analysis.

Results of the analysis are listed in Tab. 3. At the chromatographic analysis, there was a slight number of oxygen registered in gas products.

The oxygen must have entered the sample only at its removal from the device. If we consider the pyrolytic process, it is not possible that the created pyrolytic gas contained oxygen because oxygen in waste is used at reactions in the reaction zone for creating $\mathrm{CO}, \mathrm{CO}_{2}$ and liquid fractions of pyrolysis. This oxygen influences the real composition of pyrolytic gas therefore at processing the results it was deducted from the total volume. Also, it is necessary to deduct nitrogen out of the total volume because it formed a part of the absorbed air and it was creating inert atmosphere in the pyrolytic furnace.

Tab. 3. Chromatographic analysis of the pyrolytic process gas product for the RR and PF sample

\begin{tabular}{|c|c|c|c|c|c|c|}
\hline \multicolumn{7}{|c|}{ Chromatographic analysis of the pyrolytic process gas product } \\
\hline & \multirow{2}{*}{\multicolumn{3}{|c|}{$\begin{array}{l}\text { RR sample } \\
\text { temperature }\end{array}$}} & \multirow{2}{*}{\multicolumn{3}{|c|}{$\begin{array}{l}\text { PF sample } \\
\text { temperature }\end{array}$}} \\
\hline & & & & & & \\
\hline Content (\%) & $600^{\circ} \mathrm{C}$ & $600-800^{\circ} \mathrm{C}$ & $800^{\circ} \mathrm{C}$ & $600^{\circ} \mathrm{C}$ & $600-800^{\circ} \mathrm{C}$ & $800^{\circ} \mathrm{C}$ \\
\hline $\mathrm{CH}_{4}$ & 7.12 & 8.63 & 9.40 & 6.12 & 7.52 & 8.69 \\
\hline $\mathrm{H}_{2}$ & 6.95 & 12.31 & 18.1 & 5.41 & 8.65 & 11.41 \\
\hline $\mathrm{O}_{2}$ & 0.14 & 0.11 & 0.09 & 0.38 & 0.035 & 0.34 \\
\hline $\mathrm{N}_{2}$ & 79.1 & 75.2 & 65.8 & 73.4 & 71.2 & 69.3 \\
\hline $\mathrm{CO}_{2}$ & 0.18 & 0.19 & 0.21 & 0.95 & 0.35 & 0.21 \\
\hline co & 0.38 & 0.65 & 0.82 & 0.01 & 0.20 & 0.63 \\
\hline $\mathrm{C}_{2} \mathrm{H}_{4}$ & 5.33 & 6.80 & 4.48 & 3.15 & 1.89 & 0.98 \\
\hline $\mathrm{C}_{2} \mathrm{H}_{6}$ & 0.20 & 0.48 & 0.56 & 0.15 & 0.056 & 0.027 \\
\hline $\mathrm{C}_{2} \mathrm{H}_{2}$ & 0.29 & 0.36 & 0.89 & 0.33 & 0.27 & 0.45 \\
\hline $\mathrm{C}_{58}$ & 0.30 & 0.30 & 0.29 & 0.087 & 0.04 & 0.055 \\
\hline$C_{4}$ & 0.59 & 0.62 & 0.39 & 0.044 & 0.39 & 0.017 \\
\hline$c_{3}$ & 0.71 & 0.97 & 0.52 & 0.065 & 0.293 & 0.016 \\
\hline$Q\left(M J \cdot \mathrm{Nm}^{-3}\right)$ & 37.14 & 38.15 & 39.60 & 33.26 & 35.41 & 36.15 \\
\hline
\end{tabular}

\section{DISCUSSION}

In the article, only influence of temperature on the process of pyrolysis for used tires liquidation is analyzed.

The loss in weight of the original sample as opposed to the weight of the original sample that represents weight conversion to liquid and gas products is shown in Fig. 4.

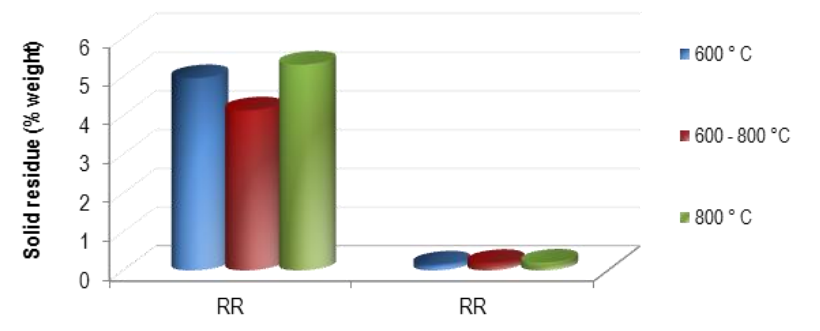

Fig. 4. Original sample conversion

The biggest conversion of weight into liquid and gas products is at $800{ }^{\circ} \mathrm{C}$. The conversion is mainly influenced by the manner of pyrolysis, i.e. if it is a slow or fast pyrolysis. In case of the carried out research it is monitoring of the heating speed influence. The next factor influencing conversion is chemical purity of the material being liquidated by pyrolysis. High value of conversion is important at waste removal because the effort is to significantly reduce the weight of waste. Weight division into the individual products in \% as opposed to the original sample weight is shown in Fig. 5.

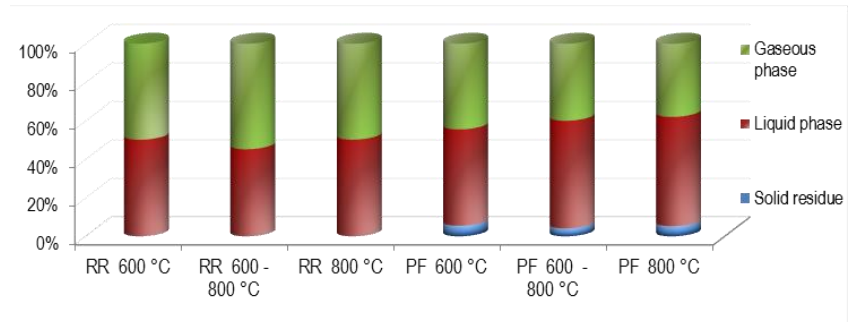

Fig. 5. Tire sample division to individual products

From the graphic scheme it is clear that at fast pyrolysis (at thermal interval of 600 up to $800{ }^{\circ} \mathrm{C}$ ) the share of gas product is in average $55 \%$. Within combined pyrolysis it is clearly confirmed that there is the biggest share of gas product as towards the pyrolysis at constant temperature.

Considering the results of pyrolytic process and creation of pyrolytic products it is possible to state that using this technology there is a precondition of continuous energetic usage of mainly gas products - products with the biggest weight share. Volume of the created gas product, registered at the end of the measurement and counted considering $1 \mathrm{~g}$ of sample weight is shown in Fig. 6. Volume of the created pyrolytic gas increases with increased temperature in the interval of 600 to $800{ }^{\circ} \mathrm{C}$. There is a precondition that the volume of created gas product depends on the volume of volatile combustible. However, clear confirmation of this hypothesis is not possible due to the fact that the volume of volatile combustible was not examined before the laboratory test.

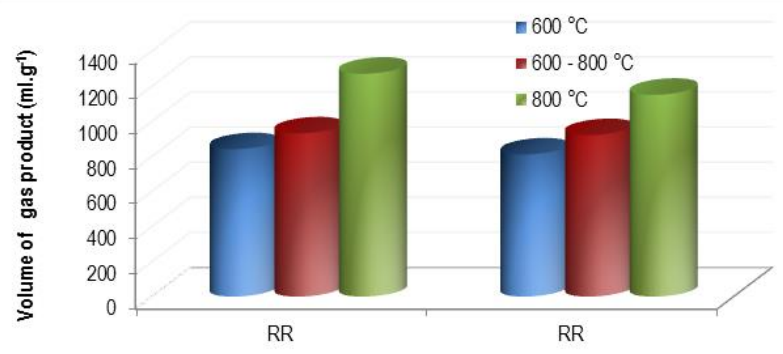

Fig. 6. Volume of created gas product

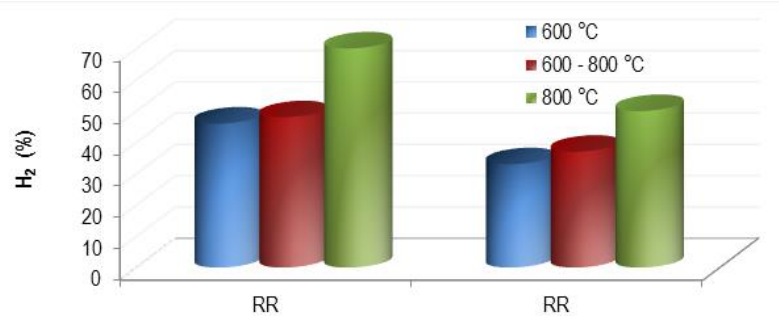

Fig. 7. Creation of hydrogen under the influence of temperature

In response to the creation of gas product it is important to monitor the share of combustible and non-combustible elements of pyrolytic gas. Out of their quantitative share at concrete temperatures of the pyrolytic process it is possible to set the 
temperature influence to their creation. Content of the individual elements $\left(\mathrm{H}_{2}, \mathrm{CO}, \mathrm{CO}_{2}, \mathrm{CH}_{4}, \mathrm{C}_{2} \mathrm{H}_{4}\right)$ depending on temperature is shown in Figs. 7 to 11. It is clear from Fig. 8 that with increased temperature also volume of $\mathrm{H}_{2}$ increases and volume of carbohydrates $\mathrm{CH}_{4}$ decreases.

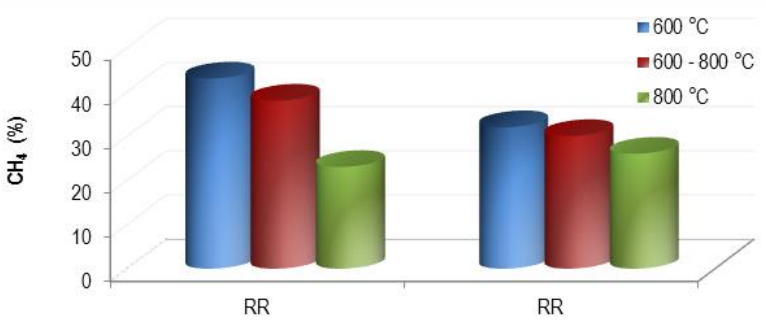

Fig. 8. Creation of methane influenced by temperature

Due to the fact that methane has higher thermal capacity than hydrogen, it is necessary to consider it for usage of the gas product. In case the gas product is to be used from the point of view of its heating characteristics, it is more convenient to use the pyrolytic gas product being created at $600{ }^{\circ} \mathrm{C}$ which is richer in methane, but at creation of less volume of this gas. In case the highest volume possible is to be obtained at the lowest solid residue, it is necessary to apply pyrolysis at $800^{\circ} \mathrm{C}$.

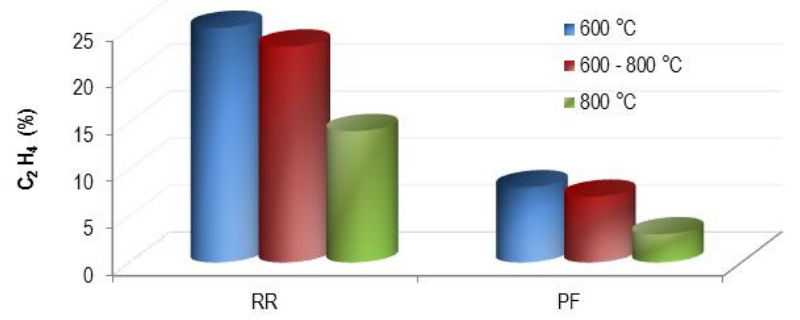

Fig. 9. Creation of ethylene influenced by temperature

The influence of temperature for ethylene creation has the same effect as within methane. That means higher volume share of ethylene is registered at temperature of $600{ }^{\circ} \mathrm{C}$. The value of $\mathrm{CO}$ does not significantly changes with temperature (Fig. 10). Influence of increasing temperature to creation of $\mathrm{CO}$ is not as significant as within hydrogen or methane. The value of $\mathrm{CO}$ as well as $\mathrm{CO}_{2}$ (Fig. 11) depends on the volume of oxygen in the original sample.

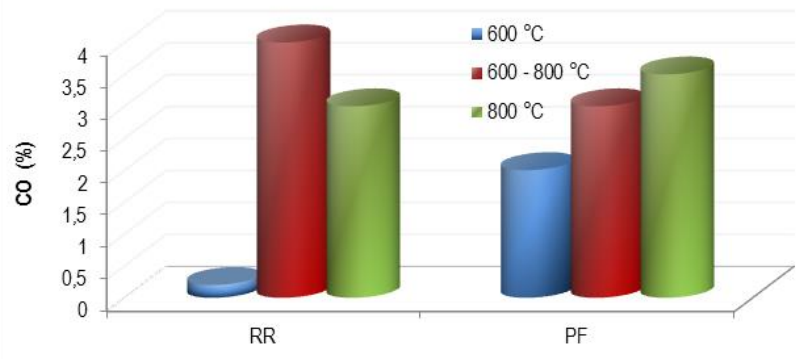

Fig. 10. Creation of carbon monoxide influenced by temperature
Used tires do not have clear chemical structure and they contain some volume of oxygen in various additives.

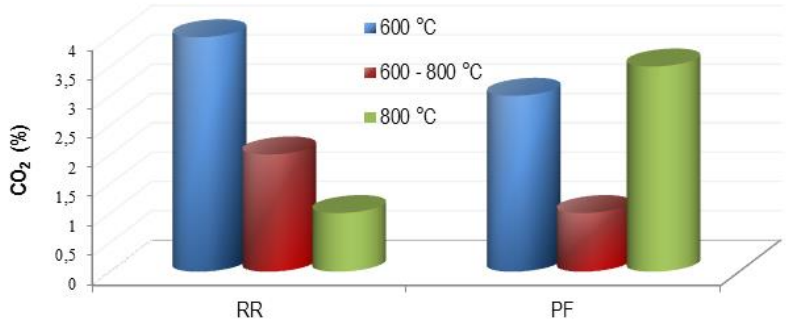

Fig. 11. Creation of carbon dioxide influenced by temperature

\section{CONCLUSION}

At present, many methods of pyrolytic processes are known and they significantly differ from each other in period of time of keeping the material in pyrolytic reactor, in temperature at which there is combustion created, in volume of created heat and also in created products of pyrolysis.

Current manners of used tires liquidation are not suitable mainly from the point of view of environment protection. Pyrolysis seems to be one of the possible solutions of minimizing the permanently increasing waste; within this technology also with a significant economic effect.

Using pyrolysis as a method of energetic recovery of used tires depends on sales of the pyrolytic products. Therefore, characteristics of the pyrolytic products and possibilities of their further application in technological processes are important. Currently, mainly solid products of pyrolysis are used, such as active carbon or solid residues are used in reinforcements in rubber industry. Liquid pyrolytic products are used as fuel or source of chemical matters and pyrolytic gas is re-used for pyrolytic process. temperature (above all, chosen thermal interval of pyrolytic process duration) and heating speed of the liquidated sample.

The aim of this work was to draw attention to the influence of operational parameters on final products of the pyrolytic process. As it results from the experiment, the most significant parameter that influences the final products of pyrolysis is temperature (above all, chosen thermal interval of pyrolytic process duration) and heating speed of the liquidated sample.

\section{REFERENCES}

1. Aylón E. et al. (2007), Emissions from the combustion of gas-phase products at tyre pyrolysis, Journal of Analytical and Applied Pyrolysis, 79, 210-214.

2. Berrueco C., Esperanza E., Mastral F. J. et al. (2005), Pyrolysis of waste tyres in an atmospheric static-bed batch reactor, Analysis of the gases obtained, Journal of Analytical and Applied Pyrolysis, $74,245-253$.

3. Cunliffe A. M., Williams P. T. (1998), Composition of oils derived from the batch pyrolysis of tyres, Journal of Analytical and Applied Pyrolysis, 44, 131-152.

4. Haydary J. et al. (2012), Influence of particle size and kinetic parameters on tire pyrolysis, Journal of Analytical and Applied Pyrolysis, 97, 73-79.

5. Kizek J., Zsigraiová Z. (1999), Experimental study of combustion parameters of low-heat gaseous fuels, Metallurgičeskaja 
Teplotechnika, Gosudarstvennaja Metalurgičeskaja Akademija Ukrajiny, 17-19.

6. Koreňová Z. et al. (2006), Kinetics of Pyrolysis and properties of Carbon Black from a Scrap Tire, Chemical Paper, 60, 422-426.

7. Leung D. Y. C., Wang C. L. (1998), Kinetic study of scrap tyre pyrolysis and combustion, Journal of Analytical and Applied Pyrolysis, 45, 153-169.

8. Murena F., Garufi E., Smith R.B., Gioia F. (1996), Hydrogenative pyrolysis of waste tires, Journal of Hazardous Materials, 50, 79-98.

9. Rodriguez I. M., et al. (2001), Pyrolysis of scrap tyres, Fuel Processing Technology, 72, 9-22.
10. Wágnerová E., Uríček D. (2003), Theoretical analysis of thermal methods of disposal of municipal waste, Acta Mechanica Slovaca, 7 , 337-342.

11. Yang J., Tanguy P. A., Roy C. (1995), Heat transfer, mass transfer and kinetics study of the vacuum pyrolysis of a large used tire particle, Chemical Engineering Science, 50, 1909-1922.

Acknowledgement: The article was created thanks to the support of the agency of the Ministry of Education, Science, Research and Sport of the Slovak Republic for structural funds of the EC of the operational program "Research and development", project no. ITMS 26220220044. 